\title{
ASPECTOS AMBIENTAIS DAS ÁREAS SUSCEPTÍVEIS À DESERTIFICAÇÃO E CARACTERÍSTICAS SOCIOAMBIENTAIS DO NÚCLEO DE DESERTIFICAÇÃO DO SERIDÓ DO RIO GRANDE DO NORTE (RN) E PARAÍBA (PB)
}

\author{
M. S.LUCENA ${ }^{1}$
Universidade Federal de Campina Grande
marceloslucena@hotmail.com ${ }^{1}$
}

Artigo submetido em 04/01/2016 e aceito em 24/06/2019

DOI: 10.15628/holos.2019.3938

\section{RESUMO}

Apesar da relevância, as discussões e a disseminação de informações, a execução de medidas para o enfretamento da desertificação praticamente não têm sido executadas. Neste sentido, este trabalho visa apresentar uma síntese de informações sobre os aspectos ambientais das áreas susceptíveis à desertificação no Semiárido brasileiro e apresentar as características socioambientais relacionadas mais diretamente com a desertificação no Seridó do Rio Grande do Norte e Paraíba. Para tal, foi realizada pesquisa onde se efetuou consulta a livros, documentos institucionais, periódicos especializados, artigos científicos e acesso a bancos de dados, por meio de expressões em português que dissessem respeito à desertificação, áreas susceptíveis à desertificação, núcleo de desertificação e núcleo de desertificação do Seridó. Constatou-se que as ASD, no Brasil, ocupam 1.340.000 $\mathrm{km}^{2}$, sendo a região semiárida sua principal integrante. Nas ASD, predominam índices pluviométricos abaixo de $800 \mathrm{~mm}$, com alta evapotranspiração potencial. Os solos, com longa ocupação humana e sensibilidade à erosão de moderada a alta, apresentam os seguintes níveis de degradação: 40,80\% "moderado"; 27,68\% "grave" e $5,86 \%$ "muito grave". A Caatinga é bioma predominante, onde $46,4 \%$ do território apresentam-se antropizados. No Seridó RN/PB, as implicações das atividades econômicas predominantes, caracterizadas por intensa extração de lenha, para utilização na indústria ceramista e em pequenas indústrias urbanas, e pela utilização crescente das terras, antes voltadas à agricultura, para a produção pecuária, estão forjando um quadro de degradação ambiental, requerendo, em função de suas características naturais, um modelo de aproveitamento econômico adequado às condições semiáridas.

PALAVRAS-CHAVE: Semiárido, Núcleo de Desertificação, Seridó, Aspectos socioambientais.

\section{ENVIRONMENTAL ASPECTS OF AREAS SUSCEPTIBLE TO DESERTIFICATION AND SOCIO-ENVIRONMENTAL CHARACTERISTICS OF THE DESERTIFICATION CENTER OF RIO GRANDE DO NORTE (RN) AND PARAÍBA (PB)}

\section{ABSTRACT}

Despite the relevance, discussions and dissemination of information, the execution of measures to cope with desertification have barely been implemented. Therefore, this paper aims to present a synthesis of information on the environmental aspects of the areas susceptible to desertification in the Brazilian semi-arid region and to present the socio-environmental characteristics most directly related to desertification in the Seridó do Rio Grande do Norte and Paraíba. For that, Where it was consulted books, institutional documents, specialized periodicals, scientific articles and access to databases, through expressions in Portuguese that related to desertification, areas susceptible to desertification, center of desertification and desertification center of Seridó. It was found that there are 1,340,000 $\mathrm{km}^{2}$ of ASD in Brazil, which occur mostly in the semiarid region. In the ASD, prevailing rainfall indices below $800 \mathrm{~mm}$, with high potential evapotranspiration. The soils, which have long been used by humans and are moderately to highly sensitive to erosion, have the following levels of degradation: $40.80 \%$ (moderate), $27.68 \%$ (high) and $5.86 \%$ (very high). The Caatinga is the predominate biome, and $46.4 \%$ of this territory has been influenced by humans. In Seridó RN / PB, as implications of the predominant economic characteristics, characterized by intense extraction of firewood, for use in the ceramist industry and in small urban industries, and in increasing use of previously agricultural land for livestock production, are forging a picture of environmental degradation, requiring, according to their natural characteristics, a model of economic use appropriate to semi-arid conditions.

KEYWORDS: Semiarid, Desertification Center, Seridó, Socio-environmental aspects. 


\section{INTRODUÇÃO}

Os estudos sobre a desertificação, no Brasil, ganharam destaque a partir de Vasconcelos Sobrinho na década de 1970, oportunidade em que alertava para o surgimento de um "deserto" no semiárido brasileiro, em decorrência de condições ambientais específicas e práticas de manejo inadequadas. A partir de então, o processo de desertificação no semiárido brasileiro tem sido considerado um dos mais graves problemas de ordem socioambiental que a região enfrenta.

De acordo com Perez-Marin, Cavalcante, Medeiros, Tinôco \& Salcedo (2012), as áreas susceptíveis à desertificação, no Brasil, abrangem $1.340 .863 \mathrm{~km}^{2}$, englobando cerca de 1488 municípios dos nove Estados do Nordeste, além de alguns municípios setentrionais no norte de Minas Gerais e Espírito Santo. Nessas localidades, é preocupante o atual estado da degradação das terras e da desertificação. É uma situação claramente identificável e se reflete nos históricos problemas de secas, da pobreza, da fome e das migrações (Rêgo, 2012).

O Programa de Ação Nacional de Combate à Desertificação e Mitigação dos Efeitos da Seca - PAN-Brasil, conforme o Ministério do Meio Ambiente [MMA], identificou na região semiárida nordestina quatro áreas com alto risco à desertificação, em que se deveriam concentrar as ações contidas no plano. Elas foram denominadas Núcleos de Desertificação e os principais do Nordeste brasileiro são os seguintes: Gilbués-PI; Irauçuba-CE; Cabrobó-PE e Seridó-RN/PB [MMA, 2005).

Santana (2007) relaciona como os principais aspectos ambientais de áreas susceptíveis à desertificação, as condições de solo, precipitação pluviométrica, aspectos morfológicos e hipsométricos do relevo, o bioma predominante, as formações vegetais e seu status de conservação. Perez-Marin et al. (2012); Alves, Souza e Nascimento (2009) elencam como características socioambientais, de implicação mais direta sobre a desertificação, as formas de utilização dos recursos naturais, especialmente o manejo aplicado ao solo e à vegetação, os aspectos das práticas agropecuárias, como a retirada da vegetação nativa para substituição por pastos e plantações agrícolas, as queimadas e a mineração desordenada.

O Seridó RN/PB é uma região fitogeográfica que abrange parte dos estados do Rio Grande do Norte e Paraíba. Essa região tem como principais atividades econômicas a agropecuária, a exploração dos recursos florestais nativos para lenha e carvão e a mineração. A ausência de racionalidade no uso dos recursos naturais resultou na degradação, especialmente a deflagração do processo de desertificação.

Em relação ao Seridó $\mathrm{RN} / \mathrm{PB}$. há um déficit de estudos e de informações sistemáticas, que façam uma reflexão sobre as áreas sob desertificação, especialmente aquelas que debatam a realidade físico-climática, ambiental e os principais fatores da degradação ambiental do Seridó $\mathrm{RN} / \mathrm{PB}$, que possam ser uma fonte de consulta e o passo inicial sobre as discussões sobre a desertificação em caráter local, enfatizando causas e implicações mais imediatas.

Dessa forma, o presente trabalho objetiva apresentar uma síntese de informações sobre os aspectos ambientais das áreas susceptíveis à desertificação no Semiárido brasileiro e apresentar as 
características socioambientais relacionados mais diretamente com a desertificação no Seridó do Rio Grande do Norte e Paraíba.

\section{REVISÃO BIBLIOGRÁFICA}

\subsection{Processo de desertificação: origens e evolução do debate do tema}

Rêgo (2012) atribui a três vertentes o início das discussões sobre a desertificação. Primeiramente, o francês Louis Lavaudeu teria, em 1927, relatado em artigo, o empobrecimento dos arvoredos do sul da Tunísia, afirmando que a desertificação era um processo de procedência antrópica. Outro francês, André Aubréville teria, em 1949, no livro "Climats, Forêts et Desértification de l'Afrique tropicale", caracterizado a substituição das florestas tropicais e subtropicais por savanas, entendendo que o processo de degradação era fruto do uso predatório dos recursos. A terceira vertente credita aos estudos norte-americanos relativos à desertificação, a partir de processos de degradação que ocorreram no meio-oeste daquele país, a origem do debate sobre este tema. Nessa região, o desmatamento e a intensificação da exploração dos solos pela agricultura e pecuária, agravados por uma forte seca entre 1929 e 1932, teriam causado o fenômeno de tempestades de poeira conhecido como Dust Bowl.

No Brasil, embora não tratada de forma oficial e científica, a preocupação com a desertificação também existia, anteriormente aos relatos francês e americano. Euclides da Cunha em 1902, em Os Sertões, dedica atenção à relação peculiar do homem com a terra dos sertões, que ele denominou "como se faz um deserto". Nas palavras de Cunha (1902, pp.32-34):

“..." Na agricultura primitiva dos silvícolas era instrumento fundamental o fogo "...". Cultivavam-na. Renovavam
o mesmo processo na estação seguinte, até que, de todo exaurida, aquela mancha da terra fosse, imprestável,
abandonada em caapuera - mato extinto "...". Veio depois o colonizador e copiou o mesmo proceder. "...."
Colaborando com os elementos meteorológicos, com o nordeste, com a sucção dos estratos, com as canículas,
com a erosão eólia, com as tempestades subitâneas - o homem fez-se uma componente nefasta entre as
forças daquele clima demolidor. Se o não criou, transmudou-o agravando-o. Deu um auxiliar à degradação das
tormentas, o machado do caatingueiro; um supletivo à insolação, a queimada. Fez talvez o deserto "...".

Depois dos primeiros registros e de tentativas de elevar o assunto ao patamar de preocupação internacional e de interesse científico, somente no início de 1970, quando ocorreu uma grande seca no Sahel, região de fronteira entre o deserto do Saara e terras férteis ao sul, o mundo reconheceu os impactos socioeconômicos e ambientais da desertificação, o que culminou com a realização, em 1977, da Conferência das Nações Unidas sobre Desertificação em Nairóbi, Quênia (Rêgo, 2012).

Dessa conferência resultou: a consolidação do tema em nível mundial, o que permitiu que muitos países atentassem para seus problemas ambientais; a introdução das regiões com climas áridos e semiáridos no cenário das discussões ambientais, mostrando que os recorrentes problemas de pobreza e meio ambiente necessitavam de um enfretamento direto pela comunidade internacional; e, por último, a criação do Plano de Ação mundial contra a Desertificação (Alves et al., 2009). 
Rêgo (2012) afirma que o termo "desertificação" sempre foi um conceito ambíguo. Para ele, não existia objetividade, pois no início dos debates havia controvérsia sobre causas e consequências, além da divergência em torno do seu conceito, de sua extensão e de suas particularidades. Tal fato provocou, entre outros problemas, grandes dificuldades no diálogo entre cientistas, políticos e tomadores de decisão.

Os pontos divergentes advinham, além de diferentes metodologias utilizadas, avaliação de estimativas climáticas contraditórias e interesse políticos conflitantes, o que contribuiu para o descrédito do tema, levando muitos países a não se comprometerem com o problema. Era necessário, portanto, estabelecer um marco conceitual, aceito em nível mundial, para direcionar o estabelecimento prático de ações voltadas para elaboração de planos de ação de combate à desertificação.

Diante deste contexto, a Convenção das Nações Unidas de Combate à Desertificação, com base nos pressupostos estabelecidos pela Agenda 21, definiu em 1992, a desertificação como a degradação das terras nas zonas áridas, semiáridas e subúmidas secas, resultante da ação de fatores diversos, com destaque para as variações climáticas e as atividades humanas. A degradação da terra é compreendida como a degradação dos solos, recursos hídricos, da vegetação e da biodiversidade. A consequência do somatório destes fatores significa, por fim, redução da qualidade de vida das populações afetadas (MMA, 2005). São consideradas zonas áridas, semiáridas, secas e subúmidas secas, para efeito de enquadramento nos critérios da definição das Nações Unidas, as regiões que possuírem Índice de Aridez (Thornthwaite, 1941), entre 0,05 e 0,65. O Índice de Aridez expressa a razão entre a precipitação e a evapotranspiração potencial.

Verdum, Quevedo, Zanini e Cândido (2009) afirmam que a desertificação aparece associada à destruição do potencial biológico das terras áridas, semiáridas e subúmidas secas. Goudie (1990) apud Verdum et al. (2009) afirma que a desertificação é uma alteração na biomassa com perdas aceleradas de solo, tendo as atividades humanas e o fator climático como principais agentes. $O$ excesso de monocultura, o sobrepastejo, a salinização e o desmatamento são as principais causas humanas associadas à desertificação.

\subsection{Aspectos ambientais das ASD e características socioambientais dos Núcleos de desertificação}

Santana (2007) reúne uma série de itens que caracterizam as ASD no Brasil. Parte deles dizem respeito aos aspectos ambientais dominantes em cada localidade enquadrada como susceptível a desenvolver processos desertificação, levando em conta a definição oficial das convenção das Nações Unidas de Combate à Desertificação. Para o Centro de Estudos Estratégicos [CGEE] (2016), os aspectos ambientais das áreas susceptíveis à desertificação, no território brasileiro, não encontram paralelos em nenhuma parte do globo, não somente devido à questões climáticas, uso e ocupação dos solos, mas, primordialmente, pela cobertura vegetal única.

A primeira característica ambiental relevante é a localização das ASD. Todo o semiárido brasileiro e suas áreas de entorno, o que abrange uma área de $1.323 .975,4 \mathrm{~km}^{2}$ do território 
nacional, são enquadrados nesta categoria, por possuírem Índice de Aridez entre 0,20 e 0,65. Ademais, os aspectos ambientais se desdobram em, principalmente, condições específicas de solo, de potencialidade agrícola dos mesmos, relevo, bioma e vegetação dominante, o status da cobertura vegetal, os recursos hídricos, a distribuição hidrográfica e a vazão dos cursos d'água (Santana, 2007; CGEE, 2016).

São justamente essas condições ambientais das ASD (principalmente as de clima, solo, água e vegetação) que, associadas à pressão exercida sobre os recursos naturais pela ação socioeconômica, constituem um conjunto de características socioambientais, entre as quais destaca-se a pressão populacional, formas inadequadas de uso e ocupação do solo, uso irracional da cobertura vegetal, que vêm contribuindo para a deflagração de processos de desertificação em algumas localidades. É da interação entre condições ambientais específicas e pressão exercida pelas populações que resultam as principais ações de implicação para o desenvolvimento da desertificação. Para Rêgo (2012), a desertificação é um fenômeno complexo, para o qual concorrem fatores de diferentes índoles - ambientais, sociais, econômicos e políticos - e, é essa complexidade uma das causas de importância do fenômeno e de sua abrangência.

Os principais problemas socioambientais presentes nos núcleos de desertificação dizem respeito, em grande parte, à crescente pressão exercida sobre os recursos naturais. As características socioambientais envolvem o relacionamento do homem com o meio ambiente e a gama de recursos que o circunda. Aquelas que têm implicação mais direta sobre a desertificação envolvem as formas de utilização dos recursos naturais, especialmente o manejo aplicado ao solo e à vegetação, os aspectos das práticas agropecuárias, como a retirada da vegetação nativa para substituição por pastos e plantações agrícolas, as queimadas, a mineração desordenada. Esse conjunto de fatores leva, ao longo do tempo, à erosão do solo, perda da capacidade produtiva, diminuição da capacidade de retenção de água pelo solo, raleamento da cobertura florestal, empobrecimento florístico e perdas de biodiversidade, tendo como resultado plausível a desertificação (Perez-Marin et al., 2012; Alves et al., 2009).

2.3 Núcleos de desertificação: a necessidade de estudos da desertificação em nível local

Matallo Junior (2001) afirma que a formulação da categoria "núcleo de desertificação" foi um dos artifícios encontrados pelo Prof. e pioneiro dos estudos de desertificação no Brasil, João Vasconcelos Sobrinho, para permitir o estudo aprofundado do fenômeno em áreas específicas, ou seja, proporcionar uma abordagem da desertificação em nível local. Na contextualização dos núcleos, proposta por Vasconcelos Sobrinho, primeiramente apareceram as "áreas piloto", que eram tidas por Vasconcelos Sobrinho como necessárias a um melhor detalhamento, pois não haveria como realizar um estudo abrangente em áreas extensas. Por este motivo, os núcleos de desertificação devem ser considerados unidades mínimas, a partir das quais os estudos sobre desertificação devem ser conduzidos, para possibilitar comparações entre resultados, causas, velocidade de acometimento, recuperação e consequências e implicações socioambientais entre os núcleos. 
Por meio de estudos e visitas em campo, voltados para a Preparação do Plano Nacional de Combate à Desertificação, em seis áreas piloto para investigação do Processo de Desertificação no semiárido brasileiro, foi possível a identificação de quatro núcleos de desertificação (Gilbués-PI, Irauçuba-CE, Seridó-RN/PB e Cabrobó-PE), nos quais a principal causa da intensa degradação foi a retirada da vegetação de Caatinga para substituição pela agricultura e pecuária, bem como pela mineração (Gilbués), extração de argila em solos aluviais e retirada de madeira para lenha no Seridó (MMA, 2005). Nos quatro núcleos verificou-se que o fator antropogênico foi determinante para a intensa degradação dos recursos naturais, através de atividades econômicas essencialmente extrativistas, de prática quase geral e recorrente (Santana, 2007).

Em função das condições de clima, solo, água e vegetação, associadas à pressão antrópica existentes nas ASD, há a deflagração de intensos processos de degradação ambiental em algumas sub-regiões das ASD, resultando na formação de manchas de solo desnudas, que são extensas áreas caracterizadas por solos rasos, com pouca capacidade de retenção de água e baixa fertilidade. Essas manchas, que indicam a formação dos núcleos de desertificação, apresentam a camada superficial do solo fortemente erodida e vegetação que apresenta dificuldade em se regenerar, em decorrência da degradação do solo. Nos núcleos de desertificação, a principal consequência das intervenções humanas é a erosão, particularmente a laminar (MMA, 2005).

Alves et al. (2009) apontam que nos núcleos de desertificação, a vegetação se recupera muito lentamente ou então é substituída por algumas espécies mais xerófilas da Caatinga. Aliado a esse fator, Perez-Marin et al. (2012) afirmam que o predomínio fundiário de pequenas propriedades, nas quais predomina o uso intensivo dos solos, associado a práticas de manejo inadequadas, resultam na perda da fertilidade dos solos, onde os níveis de fósforo e nitrogênio estão associados aos baixos teores de matéria orgânica. As práticas agropecuárias adotadas, caracterizadas pela grande lotação dos pastos e técnicas inadequadas de manejo do solo, juntamente com a depreciação da cobertura vegetal, têm propiciado sérios prejuízos às terras, culminando na redução das áreas produtivas. O resultado mais imediato é aumento a pressão nas áreas ainda produtivas, retroalimente um sistema de degradação.

De acordo com o MMA e Secretaria de Recursos Hídricos do RN [SERHID]), a configuração dos núcleos resulta do rompimento de um equilíbrio ecológico sensível, determinado por fatores naturais e humanos. Os núcleos de desertificação são redutos onde a degradação ambiental é maximizada e os efeitos da conjugação de variáveis naturais e humanas se evidenciam de forma clara, deixando transparecer no espaço a deterioração das relações socioambientais (MMA \& SERHID, 2005).

A partir dos estudos realizados conjuntamente pela Sudene e por Vasconcelos Sobrinho, foi reconhecida a existências de seis áreas piloto consideradas como críticas com relação à desertificação. Contudo, vale destacar que no mapeamento MMA (1998) foram incluídos apenas quatro núcleos (Gilbués, Irauçuba, Seridó e Cabrobó) e por motivos não esclarecidos pelo MMA, os núcleos de Sertão Central e Sertão de São Francisco não foram incluídos na lista. Atualmente, se enquadram nesta categoria as regiões do Seridó, (RN/PB), Cariris Velhos (PB), Inhamuns (CE), 
Gilbués (PI), Sertão Central (PE) e Sertão do São Francisco (BA). Segundo Perez-Marin (2015), esses locais se constituem a expressão da inadequação e ausência de práticas conservacionistas, quando da interação entre as ações produtivas e os recursos naturais (Instituto Nacional do Semiárido [INSA], 2014);

\section{METODOLOGIA}

Este estudo constitui-se de uma pesquisa a respeito da desertificação, realizada entre agosto e dezembro de 2015 , onde se efetuou consulta a livros, documentos institucionais, periódicos especializados, artigos científicos e acesso a bancos de dados. A busca pelos materiais adequados foi realizada utilizando portal de periódicos, Google Acadêmico, buscas livres na Web e Biblioteca Setorial do Centro de Saúde e Tecnologia Rural da Universidade Federal de Campina Grande, por meio de expressões em português que dissessem respeito à desertificação, áreas susceptíveis à desertificação, núcleo de desertificação e núcleo de desertificação do Seridó. Estas foram, também, as principais palavras-chaves utilizadas na busca.

Após o levantamento do material, se avaliou aqueles que continham descritores que reportassem ao escopo da pesquisa e que comportassem as informações mais atualizadas sobre os temas propostos, dando-se preferência aos documentos de instituições e órgãos oficiais. Como forma de avaliação e análise do conteúdo do material pesquisado, buscou-se estabelecer uma escala de estudo, partindo-se de um processo mais amplo, que é a desertificação, até a reunião de informações de caráter local, relacionadas ao núcleo de desertificação do Seridó RN/PB. Nesse caminho, foram estudadas condições ambientais, climáticas, status de conservação, causas e consequências da desertificação de interesse para cada item da escala, abordando aspectos específicos em cada caso.

\section{RESULTADOS E DISCUSSÃO}

No Brasil, existe uma extensa área que, por suas condições físicas, climáticas, ambientais e de intervenções antrópicas, é susceptível ao desenvolvimento da desertificação. Com a finalidade de delimitar o escopo das ações de identificação, mitigação, medidas de combate e de se promoverem estudos e pesquisas sobre desertificação no país é que se fez a delimitação das áreas susceptíveis à desertificação (ASD). No Seridó RN/PB, os aspectos ambientais favorecem a susceptibilidade da região à desertificação, onde a longa ocupação humana e o potencial de degradação imposto pelas atividades econômicas, como a extração de lenha e pecuária extensiva, proporcionaram a redução das áreas de Caatinga, raleamento da vegetação, exposição dos solos e consequente degradação, culminando em um quadro muito grave de desertificação.

\section{1 Áreas susceptíveis à desertificação (ASD) no Brasil e seus aspectos ambientais}

Segundo o Atlas das áreas susceptíveis à desertificação do Brasil (Santana, 2007), as ASD abrangem o trópico semiárido, subúmido seco e suas áreas de entorno, ocupando cerca de 
1.340.000 km², englobando partes dos Estados do RN, PB, PE, CE, PI, BA, AL, SE, MA, MG e ES, atingindo diretamente 30 milhões de pessoas. Desse total, atualmente $180.000 \mathrm{~km}^{2}$ já se encontram em processo grave e muito grave de desertificação.

As áreas de entorno das ASD foram incluídas, mesmo não apresentando um padrão climático que se enquadre na definição adotada. A razão para tal é o fato delas apresentarem características comuns às áreas semiáridas e subúmidas secas. Esses critérios dizem respeito à incidência de secas, presença do Bioma Caatinga e serem enquadradas pela Lei $n^{\circ} 9.690$ de 15.07.1998, como áreas de atuação da SUDENE (Santana, 2007). A abrangência total das áreas susceptíveis à desertificação supera a atual delimitação do semiárido brasileiro, na qual, em 2000, havia uma densidade demográfica de 23,66 hab./ $\mathrm{km}^{2}$ (MMA, 2005). A região semiárida brasileira, como principal integrante das ASD, tem, de acordo com a atualização e conclusões do Grupo de Trabalho Interministerial, uma área de $982.563 \mathrm{~km}^{2}$. A nova delimitação abrange 1133 municípios, que atenderam aos seguintes critérios: i) precipitação pluviométrica média inferior a $800 \mathrm{~mm}$ (isoeita de $800 \mathrm{~mm}$ ); ii) índice de aridez de até 0,5 no período entre 1961 e 1990; e iii) risco de seca maior que 60\% no período entre 1970 e 1990 (PEREIRA, 2007).

\subsubsection{Regime pluviométrico das ASD}

Nas ASD ocorre grande variação dos índices médios de chuva (600 a 2100 mm). Os menores valores de precipitação pluviométrica ocorrem na divisa Bahia/Pernambuco e na região Sudoeste do Piauí. As regiões mais chuvosas situam-se nas proximidades das áreas litorâneas, com exceção da zona costeira do Estado do RN. A pouca chuva e a ocorrência de altas temperaturas resultam em altos índices de evapotranspiração e grande potencial de suscetibilidade à erosão (Santana, 2007).

Segundo o Centro de Desenvolvimento e Planejamento Regional [CEDEPLAR] e Fundação Oswaldo Cruz [FIOCRUZ] (2009) e Santana (2007), se considerarmos um quadro de mudanças climáticas, em seu cenário que prevê alterações climáticas mais drásticas (A2), haverá um aumento de quase $4^{\circ} \mathrm{C}$ na temperatura, e mesmo apesar anomalias positivas no regime das chuvas, esperase que ocorra um processo de "aridização" no Nordeste, em razão das elevadas temperaturas proporcionarem um aumento na evapotranspiração e diminuição da disponibilidade hídrica, ampliando as áreas susceptíveis à desertificação e redução de terras aptas à agropecuária.

Nesse sentido, em 2007 o Inpe apresentou projeções climáticas para o Brasil até 2100, onde foram desenvolvidos modelos regionais de clima com alta resolução, que serviram de base para uma série de estudos publicados em 2008. Esses e outros estudos reforçam a noção de que o Nordeste é a região brasileira mais suscetível aos efeitos do aquecimento global, com possível queda na produção agrícola e redução na geração de energia (CEDEPLAR \& FIOCRUZ, 2009).

\subsubsection{Solos nas ASD}

Para Santana (2007), os solos que predominam nas ASD são, principalmente, os Latossos (30\% das áreas da ASD); Argissolos (15\%); Luvissolos crômicos ( 9\%), com ocorrência mais marcante na região mais afetada pelas secas, principalmente em PE, PB, CE e RN; os Neossolos Litólicos (15\%) 
acontecem nas regiões com relevos ondulados a fortemente ondulados, sendo, por isto, mais susceptíveis à erosão; Neossolos Quartzarenicos (9\%) e Planossolos ( 8\%) (Tabela 1).

Tabela 1: Níveis de degradação ambiental por classe de solo nas ASD

\begin{tabular}{|c|c|c|c|c|}
\hline $\begin{array}{c}\text { NÍVEIS DE } \\
\text { DEGRADAÇÃO }\end{array}$ & TIPOS DE SOLOS & RELEVO & $\begin{array}{l}\text { SENSIBILIDADE } \\
\text { À EROSÃO }\end{array}$ & $\begin{array}{l}\text { TEMPO DE } \\
\text { OCUPAÇÃO }\end{array}$ \\
\hline Severo & Luvissolos & $\begin{array}{l}\text { Suave ondulado e } \\
\text { Ondulado }\end{array}$ & Forte & Longo (Algodão) \\
\hline Acentuado & Neossolos & $\begin{array}{c}\text { Ondulado, Forte } \\
\text { ondulado e Montanhoso }\end{array}$ & Muito forte & $\begin{array}{l}\text { Recente (Cultura } \\
\text { de subsistência) }\end{array}$ \\
\hline Moderado & $\begin{array}{l}\text { Luvissolos, Nitossolos, } \\
\text { Cambissolos }\end{array}$ & $\begin{array}{c}\text { Ondulado e Forte } \\
\text { Ondulado }\end{array}$ & Moderado & $\begin{array}{l}\text { Longo (Culturas } \\
\text { comerciais) }\end{array}$ \\
\hline Baixo & Planossolos & $\begin{array}{l}\text { Plano e Suave } \\
\text { ondulado }\end{array}$ & Moderado & $\begin{array}{l}\text { Médio (cultura de } \\
\text { subsistência) }\end{array}$ \\
\hline
\end{tabular}

Fonte (PAN-Brasi - MMA, 2005, adaptada)

$\mathrm{Na}$ região semiárida do Nordeste, onde predominam as ASD, 74,34\% do território apresentam diferentes graus de comprometimento, com 40,80\% correspondendo ao grau "moderado", 27,68\% "grave" e 5,86\% "muito grave" (Tabela 2).

Tabela 2: Grau de comprometimento, área e população afetada pela desertificação no semiárido brasileiro

\begin{tabular}{ccccc}
\hline GRAU DE & \multirow{2}{*}{ ÁREA $\left(\mathrm{Km}^{2}\right)$} & POPULAÇÃO EM & \multicolumn{2}{c}{ \% DO SEMIÁRIDO } \\
\cline { 4 - 5 } COMPROMETIMENTO & $52.425,00$ & 1991 (hab.) & ÁREA & POPUAÇÃO \\
\hline Muito Grave & $247.831,00$ & 7.378 .064 & 5,86 & 7,72 \\
Grave & $365.287,00$ & 6.535 .171 & 27,68 & 43,90 \\
Moderado & $665.543,00$ & 15.748 .769 & 40,80 & 36,62 \\
Total & & & 74,34 & 88,24 \\
\hline
\end{tabular}

Fonte (PAN-Brasil - MMA, 2005)

Note-se que a classificação extrema (severa e muito grave) apresenta forte discrepância; da mesma maneira, os níveis "moderado" e "baixo" apresentam forte divergência. De todo modo, os dados da Tabela 2 informam que 74,34\% da região semiárida do Fundo de Desenvolvimento do Nordeste encontram-se submetidos a alterações ambientais variadas, correspondentes aos graus "moderado" (40,80\%), "grave" (27,68\%) e "muito grave" (5,86\%) (MMA, 2005).

\subsubsection{Cobertura Vegetal nas ASD}

As ASD são cobertas por vegetação dos biomas Caatinga (na maior parte), Cerrado, Faciações da Floresta Ombrófila Densa, Floresta tropical Caducifóla, Floresta Tropical Pluvial, Floresta Tropical Subcaducifólia, Manguezal, Campo Salino e Restinga (Tabela 3).

Tabela 3: Tipos de cobertura vegetal existentes nas ASD

\begin{tabular}{ccc}
\hline TIPOS DE COBERTURA VEGETAL & \multicolumn{2}{c}{ ÁREA APROXIMADA NAS ASD } \\
\cline { 2 - 3 } & $\mathrm{Km}^{2}$ & $\%$ \\
\hline Área Antropizada & $545.242,7$ & 40,77 \\
Área de Tensão Ecológica & $179.150,7$ & 13,39 \\
Caatinga & $364.844,0$ & 27,28 \\
Cerrado & $189.077,6$ & 14,14 \\
Faciações da Floresta Ombrófila Densa & 871,3 & 0,07 \\
Floresta Tropical Caducifólia & $30.018,7$ & 2,24 \\
Floresta Tropical Pluvial & 196,7 & 0,01
\end{tabular}


Floresta Tropical Subcaducifólia

Manguezal e Campo Salino Restinga
$10.111,9$

162,1

$17.842,1$
0,76

0,01

1,33

Fonte (Santana, 2007)

Nas ASD, aproximadamente $40,8 \%$ das áreas estão antropizadas. As regiões mais afetadas correspondem aos locais que eram originalmente ocupados pela Mata Atlântica, seguido pelas áreas de Caatinga. Por outro lado, apenas $5 \%\left(66.590,45 \mathrm{~km}^{2}\right)$ estão protegidos por Unidades de Conservação; $29,8 \%$ do território estão enquadrados como área prioritária para a conservação da biodiversidade, sendo 19,3\% daquele percentual considerado categoria de prioridade extremamente elevada para a conservação da biodiversidade. Segundo o MMA (2010), nas ASD, em 2008 o remanescente de áreas com vegetação na Caatinga era de $53,6 \%$. Somente entre os anos de 2002 e 2008, a Caatinga teve sua cobertura natural suprimida em $16.576 \mathrm{~km}^{2}$, o que representa uma taxa anual média de $2.763 \mathrm{~km}^{2} /$ ano.

\subsection{Núcleo de desertificação do Seridó RN/PB}

O Panorama de Desertificação do Rio Grande do Norte afirma que o enquadramento do Seridó potiguar como núcleo de desertificação deve-se ao fato de que quase toda essa região fitogeográfica vem sendo submetida a intensos processos de prospecção mineral, a uma forte exploração de argila em solos aluviais e exploração da vegetação nativa para abastecer a indústria local, principalmente as cerâmicas. Este conjunto de atividades constitui os principais vetores para a desertificação dessa área. Estas atividades, aliadas a condições climáticas, onde predominam baixa pluviosidade, altas temperaturas e evapotranspiração potencial acentuada, condições de solos rasos, com pouca capacidade de retenção de umidade, tornam o Seridó um dos exemplos mais graves da desertificação no Nordeste (MMA \& SERHID, 2005).

Conforme o Instituto Nacional do Semiárido [INSA] (2014), a área de abrangência do núcleo de desertificação do Seridó foi expandida, para comportar territórios de Municípios do Rio Grande do Norte e Paraíba, ocupantes da região fitogeográfica do Seridó. Todos 38 os municípios integrantes do núcleo de desertificação RN/PB ocupam uma área de 15274,4Km².

Segundo o PAN-Brasil (MMA, 2005), no Rio Grande do Norte as áreas susceptíveis à desertificação ocupam aproximadamente $94 \%$ dos municípios do Estado, enquanto na Paraíba este percentual é de em torno de $93 \%$. De acordo com diagnóstico realizado pela Superintendência do Meio Ambiente na Paraíba [SUDEMA-PB] (2008) apud Alves, Souza e Nascimento (2009), cerca de $57 \%$ do território do estado possui grau muito alto de susceptibilidade à desertificação, que se estende do Seridó Ocidental, nos municípios de Várzea e São Mamede, até a microrregião de Sousa. Informações apresentadas pelo Panorama de Desertificação do Rio Grande do Norte (MMA \& SERHID, 2005) mostram que no início dos anos de 1990, a desertificação já tinha afetado $72,5 \%$ do território potiguar, em níveis de intensidade variados e sinalizavam para estatísticas preocupantes. Nesse sentido, os municípios do Seridó do RN apresentam um quadro muito grave quanto à ocorrência da desertificação. 
No entendimento do Panorama de desertificação do RN (MMA \& SERHID, 2005), a região fitogeográfica do Seridó apresenta características naturais que refletem uma "certa predisposição" para o desenvolvimento da desertificação. Perez-Marin et al. (2012) afirmam que em função das características ambientais do Seridó RN/PB, talvez haja a possibilidade de que a desertificação surja espontaneamente, havendo possibilidade de sua preexistência, mesmo na ausência da intervenção antrópica. Destarte, faz-se necessário atentar para os principais fatores geomorfológicos, climáticos, edáficos e de cobertura vegetal existente nessa região fitogeográfica, os quais apresentam particularidades excepcionais que demandam medidas específicas de convivência e desenvolvimento econômico.

A maior parte da área do Núcleo apresenta topografia acidentada, declives acentuados com presença de solos rasos e pedregosos, com baixa capacidade de retenção de água, classificados como Neossolos Litólicos e Luvissos Crômicos. No sopé das encostas podem se formar vales com a ocorrência de Neossolos Flúvicos e Planossos Solódicos. Os Neossolos Litólicos apresentam restrição ao aprofundamento do sistema radicular posto que, o contato lítico ocorre a pouca profundidade (10 a $30 \mathrm{~cm}$ ). Isto determina um reduzido volume de água e nutrientes disponíveis às plantas e pequeno volume de solo para o sistema radicular. A situação se agrava, pela ocorrência dos afloramentos rochosos. Os Luvissolos Crômicos são quimicamente muito ricos, com elevado potencial nutricional (Perez-Marin et al., 2012).

O clima segundo a classificação Köeppen (1996) é do Bswh, caracterizado por uma precipitação pluviométrica média, que em situações normais, varia entre 350 a 800; as chuvas são intensas e, em função da baixa capacidade de absorção da água pelo solo, ocorrem enxurradas; as temperaturas médias têm pequena amplitude térmica, com média máxima que pode ultrapassar $31^{\circ} \mathrm{C}$, enquanto a média mínima é de, aproximadamente $29^{\circ} \mathrm{C}$; a umidade relativa do ar varia consideravelmente ao longo do ano, com a média mínima em torno de $43 \%$ em fevereiro e máxima em torno 62\% em novembro; a insolação média anual é de aproximadamente 2900 horas, com maior intensidade entre setembro e dezembro. Em função dessas características há um balanço negativo em grande parte do ano, com deficiência hídrica e secas periódicas (Amorim, Sampaio \& Araújo, 2005; Costa, Oliveira, Accioly \& Silva, 2009).

A vegetação da Caatinga no Seridó é quase absolutamente hiperxerófila, com um aspecto arbóreo-arbustivo esparso, geralmente com pequeno porte (inferior a $7 \mathrm{~m}$ ). $\mathrm{O}$ estrato herbáceo é sazonal, quase totalmente restrito à estação chuvosa, com predominância de capim panasco. 0 número de espécies arbóreas e a produção de biomassa no Seridó são considerados baixo quando comparado com áreas mais úmidas, possivelmente influenciados pela disponibilidade hídrica (Amorim et al.,2005; Costa et al., 2009; Pereira, Andrade, Sampaio \& Barbosa, 2003; Santana \& Souto, 2006).

Contudo, Perez-Marin et al. (2012) asseveram que não obstante os condicionantes ambientais, é evidente que com a intervenção humana nessa região a desertificação tenha se consolidado. Vasconcelos Sobrinho (2002) lembra que em face da ocupação territorial do Seridó, houve acentuação do processo de desertificação, em função da pressão exercida pelas atividades 
econômicas sobre o ecossistema. Nesse sentido, faz-se necessária a adoção de abordagens que tragam à reflexão as principais formas de intervenção sobre os recursos naturais dessa região, abrangendo as dimensões sociais, econômicas políticas e culturais que estão presentes e que orientam as ações antrópicas diante do aproveitamento dos recursos naturais. De acordo com a Agência de Desenvolvimento do Seridó [ADESE] e Cooperação Técnica Alemã [GTZ] (ADESE \& GTZ, 2008), como nas demais regiões do Nordeste brasileiro, a ocupação da região do Seridó deu-se a partir da instalação das primeiras fazendas de gado, final do século XVII, geralmente às margens dos rios, pela ocasião deslocamento do gado do litoral para o interior, abrindo uma nova fronteira. $A$ pecuária foi a base da economia até meados do século XIX.

A pecuária no início e o algodão, mais tarde, a par com o cultivo de lavouras de subsistência, nas terras mais férteis, de permeio com a cotonicultura, constituíram a base econômica do Seridó. Do século XIX até meados da década de 1970, a pecuária e a cotonicultura projetaram a região no cenário nacional, uma vez que o algodão arbóreo "mocó" era cobiçado pelas indústrias, por possuir fibras longas (ADESE \& GTZ, 2008; Leite, 2000). Outra atividade importante a partir de 1930 foi a mineração, a qual atingiu seu apogeu na década de 1970. Este tripé econômico demandou a abertura de vastas áreas, o que foi realizado de modo quase irrestrito e sem nenhuma preocupação conservacionista, resultando na degradação dos solos.

Com o declínio economia algodoeira e de mineração, a busca de estratégias que minimizassem os efeitos da crise afetou a região, resultando na criação segmentos que contribuíram para a reestruturação econômica. Novas atividades produtivas ganharam destaque, tais como as cerâmicas, queijeiras, caieiras, carvoarias, olarias, doceiras, panificadoras, etc. Esse novo modelo de produção se caracteriza pela exploração expressiva dos recursos, alterando a paisagem e comprometendo a sustentabilidade (ADESE \& GTZ, 2008).

As implicações das atividades econômicas atuais, caracterizadas por intensa extração de lenha, para utilização na indústria ceramista e em pequenas indústrias urbanas, e pela utilização crescente das terras, antes voltadas à agricultura, para a produção pecuária, estão forjando novos perfis para a paisagem do Seridó. Como resultado, podemos considerar a simplificação dos ecossistemas, com a substituição da Caatinga mais densa, de porte mais elevado e de maior densidade de indivíduos, por cenários em que dominam vegetação de aspecto mais aberto, com maiores contingentes de solos expostos, favorecendo as diversas formas de erosão.

O estado de conservação do Seridó RN/PB, considerando os dados do Monitoramento do Desmatamento nos Biomas Brasileiros por Satélite (MMA, 2010), encontra-se na Tabela 4.

Tabela 4: Relação dos Municípios que compõem o Núcleo de Desertificação do Seridó RN/PB e estimativas para a antropização dos territórios

\begin{tabular}{|c|c|c|c|c|c|c|c|}
\hline Município & $U F$ & $\begin{array}{c}\text { Área } \\
\text { caatinga } \\
\left(\mathrm{km}^{2}\right)\end{array}$ & $\begin{array}{c}\% \text { de } \\
\text { Área } \\
\text { antropizada } \\
\text { até } 2008\end{array}$ & Município & U F & $\begin{array}{c}\text { Área } \\
\text { caatinga } \\
\left(\mathrm{km}^{2}\right.\end{array}$ & $\begin{array}{c}\% \text { de } \\
\text { área } \\
\text { antropizada } \\
\text { até } 2008\end{array}$ \\
\hline Currais Novos & $\mathrm{RN}$ & 864,309 & $3,43 \%$ & Taperoá & PB & 638,734 & $46,30 \%$ \\
\hline Cruzeta & $\mathrm{RN}$ & 295,559 & $32,51 \%$ & Santo André & PB & 225,820 & $56,99 \%$ \\
\hline Equador & $\mathrm{RN}$ & 265,591 & $13,36 \%$ & Gurjão & PB & 342,497 & $14,03 \%$ \\
\hline
\end{tabular}




\begin{tabular}{lcccllll} 
Carnaúba dos Dantas & RN & 245,044 & $19,13 \%$ & Parari & PB & 127,893 & $42,12 \%$ \\
Acari & RN & 610,146 & $25,15 \%$ & São José dos Cordeiros & PB & 417,497 & $33,15 \%$ \\
Parelhas & RN & 512,690 & $20,08 \%$ & Serra Branca & PB & 737,624 & $26,16 \%$ \\
Caicó & RN & 1227,835 & $29,93 \%$ & Coxixola & PB & 119,344 & $31,20 \%$ \\
Jardim do Seridó & RN & 369,384 & $29,64 \%$ & Barra de São Miguel & PB & 595,214 & $14,37 \%$ \\
Ouro Branco & RN & 253,968 & $46,90 \%$ & Caraúbas & PB & 446,843 & $20,34 \%$ \\
Santana do Seridó & RN & 188,545 & $42,33 \%$ & Congo & PB & 273,450 & $30,18 \%$ \\
Frei Martinho & PB & 244,113 & $0,40 \%$ & Camalaú & PB & 603,789 & $40,77 \%$ \\
Picuí & PB & 665,640 & $26,70 \%$ & São João do Tigre & PB & 816,150 & $19,18 \%$ \\
Baraúna & PB & 51,108 & $93,83 \%$ & São José do Sabugi & PB & 205,986 & $71,21 \%$ \\
Nova Palmeira & PB & 310,299 & $24,74 \%$ & Santa Luzia & PB & 455,969 & $32,84 \%$ \\
Pedra Lavrada & PB & 351,887 & $40,26 \%$ & Várzea & PB & 190,295 & $32,99 \%$ \\
Cubati & PB & 137,045 & $63,26 \%$ & São Mamede & PB & 530,759 & $9,40 \%$ \\
Seridó & PB & 274,958 & $42,83 \%$ & Patos & PB & 513,619 & $11,26 \%$ \\
Tenório & PB & 105,178 & $34,55 \%$ & Santa Teresinha & PB & 358,076 & $9,99 \%$ \\
Juazeirinho & PB & 468,752 & $42,21 \%$ & Cacimba de Areia & PB & 232,787 & $7,61 \%$ \\
\hline
\end{tabular}

Fonte (MMA, 2010, adaptada)

O somatório da área abrangida por estes municípios é de $15274,4 \mathrm{~km}^{2}$. Até $2008,4100 \mathrm{~km}^{2}$ estavam ocupados por atividades humanas, com diferentes percentagens de ocupação. Entretanto, não podemos concluir que o Seridó RN/PB encontra-se preservado. Os dados da Tabela 4 mostram o percentual das terras ocupadas por atividades humanas. Não se considerou, portanto, a intensidade e o nível de degradação provocada. O MMA (2010) afirma que não foram consideradas como áreas antropizadas as cicatrizes no solo, característicos de queimadas, bem como áreas modificadas em processo regenerativo. Assim, se levarmos em conta virtualmente estas áreas, certamente o estado de conservação seria menor.

Nesse sentido, Cândido, Barbosa e Silva (2002), estudando a degradação ambiental de uma área de $947,81 \mathrm{~km}^{2}$ do Seridó Paraibano, por meio da avaliação dos parâmetros vegetação, topografia, solo/geologia, ecologia, mecanização, agricultura, densidade populacional e pecuarização, encontraram que as áreas caracterizadas por degradação grave a muito grave chegaram a quase $50 \%$ da área estudada. As zonas com degradação grave têm relevo fortemente ondulado a montanhoso, solos predominantemente litólicos, terras para pastejo e mineração, presença de vegetação aberta e rala, que foi substituída pelas pastagens e para cultivo de palma.

Costa et al. (2009) ao estudarem 16 locais considerados homogêneos quanto ao parâmetro razão precipitação média anual/temperatura média anual, em uma área de $750 \mathrm{~km}^{2}$ do núcleo de desertificação do Seridó RN/PB, concluíram que nas áreas mais degradadas, abandonadas após uso agrícola, constata-se processos de desertificação, com grande dificuldade para a regeneração e que a pressão antrópica é a causa potencial do processo de degradação da vegetação de Caatinga no Seridó RN/PB.

Macedo (2007) estudando uma área de 75000 ha no Núcleo de Desertificação do Seridó RN/PB, nos municípios de Parelhas, Jardim do Seridó, São José do Sabugi e Ouro Branco, com base em comparação de imagens Landsat TM de 1987 e 2000, pôde observar, através da classificação do uso do solo (caatinga densa, caatinga semidensa, caatinga aberta, solo exposto, pastagem, área urbana, vegetação ribeirinha e açudes), que no período de 1987 a 2000, houve redução de 57\% para 
a vegetação ciliar; aumento de $113,6 \%$ de caatinga aberta; redução de $21,3 \%$ de caatinga semidensa; aumento de $70,6 \%$ para solo exposto e de $39,8 \%$ para pastagens. Ela afirma que o aumento da caatinga aberta está associado ao consumo de lenha e ao desmatamento para atividades agropecuárias.

Com o recrudescimento da pecuária, financiada por incentivos governamentais, as pastagens tendem a dominar nas áreas rurais, em substituição à agricultura e, de acordo com Vasconcelos (2015), essas mudanças ocorrem desvinculadas das áreas destinadas à lavouras, que marcaram o tradicional consórcio gado-algodão-culturas alimentares, resultando em um novo rural, distinto do anterior, que tinha a produção baseada no sistema de parceria e de moradores.

Araújo Filho (2013) afirma que, devido às práticas de exploração florestal irracional, técnicas agrícolas rudimentares e ao sobrepastejo, em extensas áreas semiáridas do Nordeste, os solos apresentam baixa produtividade e erosão laminar, caracterizados pelo aparecimento de seixos rolados, compactação do solo e exposição do horizonte $B$, que favorecem o processo de desertificação.

\section{CONSIDERAÇÕES FINAIS}

Nas ASD predominam índices pluviométricos que variam de 600 a $2100 \mathrm{~mm}$, embora na maior parte da área ocorram precipitações abaixo de $800 \mathrm{~mm}$. Os solos, com longa ocupação humana e sensibilidade à erosão de moderada a alta, apresentam os seguintes níveis de degradação: 40,80\% "moderado"; 27,68\% "grave" e 5,86\% "muito grave". A Caatinga é o bioma predominante, onde $46,4 \%$ do território apresentam-se antropizados.

No Seridó RN/PB, as implicações das atividades econômicas predominantes, caracterizadas por intensa extração de lenha, para utilização na indústria ceramista e em pequenas indústrias urbanas, e pela utilização crescente das terras, antes voltadas à agricultura, para a produção pecuária, estão forjando um quadro de degradação ambiental, requerendo, em função de suas características naturais locais, um modelo de aproveitamento econômico adequado às condições semiáridas. Em função do predomínio do atual modelo econômico e seu modo de exploração inadequada e sem preocupação com a sustentabilidade dos ecossistemas, podemos considerar uma simplificação dos ecossistemas, com a substituição das áreas de Caatinga mais densa, de porte mais elevado e de maior densidade de indivíduos, por cenários em que dominam vegetação menos densa, com maiores contingentes de solos expostos, favorecendo às diversas formas de erosão, especialmente a laminar e a eólica.

\section{REFERÊNCIAS}

Agência de Desenvolvimento do Seridó \& Deutsche Gesellschaft für Technische Zusammenarbeit GmbH (Cooperação Técnica Alemã). (2008). Diagnóstico do uso da lenha nas atividades agroindustriais do território do Seridó-RN. Caicó: Autor. Retrieved from http://adese.com.br/documentos/Publicacoes/Diagnostico Uso Lenha Atividades Agroindustriais.pd f. 
Alves, J. J. A., Souza, E. N. \& Nascimento, S. S (2009). Núcleos de desertificação no Estado da Paraíba. Raega, 17, 139-152. Retrieved from revistas.ufpr.br/raega/article/viewFile/12314/11409

Amorim, I. L., Sampaio, E. V. S. B., \& Araújo, E. L. (2005). Flora e estrutura da vegetação arbustivoarbórea de uma área de caatinga do Seridó, RN, Brasil. Acta bot. Bras, 19(3), 615-623.

Retrieved from www.scielo.br/pdf/\%0D/abb/v19n3/27377.pdf

Araújo Filho, J. A (2013). Manejo pastoril sustentável da Caatinga. Recife-PE: Projeto Dom Helder Câmara.

Cândido, H. G., Barbosa, M. P. \& Silva, M. J. (2002). Avaliação da degradação ambiental de parte do Seridó Paraibano. Revista Brasileira de Engenharia Agrícola e Ambiental, 6(2), 368-371.

Retrieved from http://www.scielo.br/scielo.php?script=sci arttext\&pid=S1415-43662002000200031.

Centro de Desenvolvimento e Planejamento Regional \& Fundação Oswaldo Cruz. (2009). Mudanças climáticas, migrações e saúde: cenários para o nordeste brasileiro, 2000-2050. Belo Horizonte: Centro de Desenvolvimento e Planejamento Regional da Universidade Federal de Minas Gerais. Retrieved from https://cedeplar.face.ufmg.br/pesquisas/migracoes saude/Cedeplar Sumario Executivo.pdf.

Centro de Gestão e Estudos Estratégicos. (2016). Desertificação, degradação da terra e secas no Brasil. Brasília: Centro de Gestão e Estudos Estratégicos. Retrieved from https://www.cgee.org.br/documents/10182/734063/DesertificacaoWeb.pdf

Costa, T. C. C., Oliveira, M. A. J., Accioly, L. J. O., \& Silva, F. H. B. B. (2009). Análise da degradação da Caatinga no núcleo de desertificação do Seridó (RN/PB). Revista Brasileira de Engenharia Agrícola e Ambiental. Campina Grande-PB, 13, 961-974. Retrieved from www.scielo.br/pdf/rbeaa/v13s0/v13s0a20.pdf

Cunha, E. Os Sertões. São Paulo: Três, 1984.

Goudie. A. S. (1990). Desert degradation. In: Techniques for desert reclamation. John Wiley \&

Sons. Chichester.

Instituto Nacional do Semiárido. (2014). Mapas dos Núcleos de Desertificação no Semiárido. 2014. Recuperado em 11, Novembro de, 2015, de http://www.insa.gov.br/noticias/insa-publicamapas-dos-nucleos-de-desertificacao-do-semiarido/\#.VnfovVkQtdg

Leite, L. C. (Coord.). (2000). Plano de Desenvolvimento Sustentável da Região do Seridó do Rio Grande do Norte - Volume 1: Diagnóstico. Caicó: Governo do RN.

Macedo, M. R. O. B. C. (2007). Uma abordagem temática e espectral de áreas passíveis à desertificação na Região do Seridó - RN/PB. Dissertação (Mestrado em Ciências Geodésicas e 
Tecnologias da Informação), Universidade Federal de Pernambuco, Recife, Pernambuco, Brasil. Retrieved from repositorio.ufpe.br:8080/xmlui/handle/123456789/3445

Matallo, H., Jr. (2001). Indicadores de Desertificação: histórico e perspectivas. Brasília: UNESCO. Retrieved from unesdoc. unesco.org/images/0012/001298/129871POR.pdf

Ministério do Meio Ambiente. (1998). Mapa de ocorrência de desertificação e áreas de atenção especial no Brasil. Brasília: MMA/SRH.

Ministério do Meio Ambiente. (2005). Programa de Ação Nacional de Combate à Desertificação e Mitigação dos Efeitos da Seca - PAN Brasil. Brasília: Centro de Informação, Documentação Ambiental e Editoração Luís Eduardo Magalhães - CID Ambiental. Retrieved from www.mma.gov.br/estruturas/sedr desertif/ arquivos/pan brasil portugues.pdf

Ministério do Meio Ambiente. (2010). Monitoramento do desmatamento nos biomas brasileiros por satélite. Brasília: Centro de Informação, Documentação Ambiental e Editoração Luís Eduardo Magalhães - CID Ambiental. $\quad$ Retrieved from www.mma.gov.br/estruturas/sbf.../relatorio tecnico caatinga 20082009 72.pdf

Ministério do Meio Ambiente \& Secretaria de Recursos Hídricos do RN. (2005). Panorama de Desertificação no Estado do Rio Grande do Norte. Natal. Autor. Retrieved from http://www.mpgo.mp.br/portalweb/hp/9/docs/monografia mmapanorama da desertificacao no ri o grande do norte.pdf.

Pereira, I. M., Andrade, L. A., Sampaio, E. V. S. B., \& Barbosa, M. R. V. (2003). Use-history effects on structure and flora of caatinga. Biotropica 35, 154-165.

Pereira, J. S., Jr. (2007). Nova Delimitação do semiárido brasileiro. Brasília-DF: Biblioteca Digital da Câmara dos Deputados, Centro de Documentação e Informação. Retrieved from http://bd.camara.leg.br/bd/bitstream/handle/bdcamara/1604/nova delimitacao jose pereira.pdf?se quence $=3$.

Perez-Marin, A. M., CAVALCANTE, A. M. B., MedeiroS, S. S., Tinôco, L. B. M. \& Salcedo, I. H. (2012). Núcleos de desertificação no semiárido brasileiro: ocorrência natural ou antrópica?. Parc. Estrat., 17(34), 87-106. Retrieved from http://seer.cgee.org.br/index.php/parcerias estrategicas/article/view/671/615.

Perez-Marin, A. M. (Cord.) (2015). Seminário Nacional de Combate à Desertificação, Degradação das Terras e Convivência com a Semiaridez para a Redução da Pobreza e um Desenvolvimento Sustentável - Contribuição da Ciência, Tecnologia, Práticas e Conhecimentos Locais. Campina Grande: Ministério da Ciência, Tecnologia e Inovação \& Instituto Nacional do Semiárido.

Retrieved from http://www.insa.gov.br/wp-content/uploads/2016/03/UNCCD.pdf.

Rêgo, A. H. (2012). Os sertões e os desertos: o combate à desertificação. Brasília: FUNAG. Retrieved from funag.gov.br/loja/download/933-Sertoes_e_os_Desertos_Os.pdf 
Santana, J. A. S., \& Souto, J. S. (2006). Diversidade e Estrutura Fitossociológica da Caatinga na Estação Ecológica do Seridó-RN. Revista de Biologia e Ciências da Terra, 6(2), 232-242. Retrieved from http://www.redalyc.org/articulo.oa?id=50060215

Santana, M.O (Org.). (2007). Atlas das áreas suscetíveis à desertificação do Brasil. Brasília: MMA.

Retrieved from www.mma.gov.br/estruturas/sedr desertif/ arquivos/129 08122008042625.pdf

SUDEMA. (2008). Superintendência de Desenvolvimento e Meio Ambiente da Paraíba. Recuperado em maio, 2008, de http://www.sudema.pb.gov.br

Thornthwaite, C.W. (1941). Atlas of climatic types in the United States. S.I. U.S: Departament of Sgriculture/Forest Service.

Vasconcelos, S. A. (2015). O definhamento do "mundo rural tradicional" da região do Seridó na transição para o período da globalização. Revista OKARA: Geografia em debate, 9(3), 495-508. Retrieved from periodicos.ufpb.br/index.php/okara/article/view/25851

Vasconcelos Sobrinho, J. (2002). Desertificação no Nordeste do Brasil. Recife: UFPE.

Verdum, R., Quevedo, D., Zanini, L. S. G., \& Cândido, L. A. (2009). Desertificação: questionando as bases conceituais, escalas de análise e consequências. GEOgraphia, 3(6). Retrieved from http://www.uff.br/geographia/ojs/index.php/geographia/article/view/68 